\title{
Interventions That Support or Involve Caregivers or Families of Patients with Traumatic Injury: a Systematic Review
}

\author{
Megan E. Shepherd-Banigan, $P h D, M P H^{1,2}$, Abigail Shapiro, MSPH ${ }^{3}$, Jennifer R. McDuffie, PhD ${ }^{1,4}$, \\ Mira Brancu, $P h D^{5,6}$, Nina R. Sperber, $P h D^{1,2,4}$, Courtney H. Van Houtven, $P h D^{1,2,4}$, \\ Andrzej S. Kosinski, $P h D^{7}$, Neha N. Mehta, MD', Avishek Nagi, MS ${ }^{7}$, and John W. Williams Jr, \\ $\mathrm{MD}, \mathrm{MHSC} \mathrm{C}^{1,4}$
}

\begin{abstract}
${ }^{1}$ Center for Health Senvices Research in Primary Care, Durham Veterans Affairs Medical Center, Durham, NC, USA; ${ }^{2}$ Department of Population Health Sciences, Duke University School of Medicine, Durham, NC, USA; ${ }^{3}$ Department of Health Behavior, Gillings School of Global Public Health, The University of North Carolina at Chapel Hill, Chapel Hill, NC, USA; ${ }^{4}$ Department of Medicine, Division of General Internal Medicine, Duke University Medical Center Durham, Durham, NC, USA; 5 VA Mid-Atlantic Region Mental lliness Research, Education and Clinical Center (MIRECC), Durham VA Medical Center, Durham, NC, USA; ${ }^{6}$ Department of Psychiatry and Behavioral Sciences, Duke University School of Medicine, Durham, NC, USA; ${ }^{7}$ Department of Biostatistics and Bioinformatics, Duke University School of Medicine, Durham, NC, USA.
\end{abstract}

BACKGROUND: Almost 40 million family caregivers care for a loved one with severe physical or cognitive impairments. The purpose of this review is to summarize evidence about the benefits of interventions to support or involve family members/caregivers of patients with trauma-related injury on caregiver, patient, and household outcomes.

METHODS: English-language peer-reviewed publications in MEDLINE, CINAHL, and PsycINFO from 1995 through December 2016 were identified. Eligible studies included RCT or quasi-experimental studies evaluating interventions designed to support or involve caregivers or family members of patients with TBI, PTSD, or polytrauma. Abstractions were completed by one reviewer and checked by a second; two reviewers independently assessed risk of bias using the Cochrane Effective Practice and Organization of Care Review Criteria.

RESULTS: Thirteen studies ( $n=9$ TBI; $n=4$ PTSD, $n=0$ polytrauma) evaluated psychological or rehabilitation interventions involving caregivers. Interventions did not improve TBI patients' functional status (standardized mean difference [SMD], 0.29 [95\% confidence interval [CI], -0.51 to 1.08$]$ ) or psychological symptoms (SMD 0.25 , CI -0.62 to 0.12 ). Qualitative analysis shows potential intervention benefit for TBI symptoms. Interventions did not improve TBI caregiver psychological symptoms (SMD - 0.26, CI - 0.57 to 0.05); however, qualitative analysis suggests mixed effects for caregiver burden and quality of life. Positive intervention effects on patients' PTSD symptoms, mental health service use, and PTSD caregivers' psychological symptoms were identified with certain interventions. Strength of evidence ranged from moderate to very low.

Electronic supplementary material The online version of this article (https://doi.org/10.1007/s11606-018-4417-7) contains supplementary material, which is available to authorized users.

Received October 27, 2017

Revised January 17, 2018

Accepted March 21, 2018

Published online May 7, 2018
DISCUSSION: Studies showed mixed patterns of intervention effects on caregiver and patient outcomes; evidence about intervention impact is inconclusive. This review is the first to identify caregiving interventions for patients with TBI and polytrauma and extends past reviews about patients with PTSD. Limitations include a small evidence base, low study quality, disparate methods, varied outcome measures, and high heterogeneity. PROSPERO Registration CRD42017053516.

KEYWORDS: traumatic injury; mental health; disability; family caregivers; informal long-term services and supports.

J Gen Intern Med 33(7):1177-86

DOI: $10.1007 / \mathrm{s} 11606-018-4417-7$

(c) Society of General Internal Medicine (outside the USA) 2018

\section{INTRODUCTION}

In the USA, 39.8 million family members and caregivers care for loved ones with severe physical, mental, and/or cognitive impairments. ${ }^{1}$ These impairments include sequelae resulting from trauma-related injuries. Veterans who have served in the most recent post-9/11 conflicts, for example, have high rates of physical injury (e.g., musculoskeletal problems, associated pain), polytrauma, traumatic brain injury (TBI), and associated post-traumatic stress disorder (PTSD). ${ }^{2}$ There are 1.1 million family members who care for veterans with substantial trauma-related impairments. ${ }^{3}$ In the general US population, an estimated 8 million US adults are afflicted with PTSD annually, ${ }^{4}$ and approximately 3.17 million adults live with a long-term disability from TBI. ${ }^{5}$ Depending on the extent of the injuries and health comorbidities, the need for intensive support from family members can last for decades. ${ }^{3}$

A family caregiver is defined as "any relative, partner, friend or neighbor who has a significant personal relationship with, and provides a broad range of assistance for, an adult with a chronic or disabling condition". ${ }^{6}$ This role is distinct from that of formal caregivers, who are licensed 
healthcare professionals, typically paid for these services. In many cases when family caregiving occurs as a natural expectation of living with a patient impaired by traumarelated conditions (e.g., TBI, PTSD), family members do not identify as a "caregiver." Yet, they provide many of the same services. Additional terms that are relevant include "informal caregivers," "care partners," "companions," "close others," and "carers." For the remainder of this paper we use the term "family caregiver" to refer more generically to persons who either provide unpaid hands-on care or help navigate the healthcare system. As a result, the Department of Veterans Affairs Health Care System (VHA) has developed an extensive program to support family members and caregivers of veterans seriously injured during military service since September 11,2001 ${ }^{7}$; most of these veterans have a diagnosis of TBI, PTSD, or polytrauma. ${ }^{8}$ This supports the idea that while family caregiving is not currently formally acknowledged in the broader US healthcare system, there is much to be learned from the role that family caregivers play in optimizing healthcare outcomes of patients with longterm trauma-related disabilities.

Caregiving may have negative implications for caregiver physical and mental health, ${ }^{9,10}$ employment, ${ }^{11,12}$ and financial security, ${ }^{13-15}$ which may affect the quality of care provided by family caregivers. However, caregiver supportive services can offset these negative effects by reducing caregiver burden and mental distress ${ }^{16,17}$ and improving patient function ${ }^{17}$ and symptoms. ${ }^{18}$ Therefore, standardized support and training may be important to optimize patient and caregiver well-being and functioning. ${ }^{19}$ To date, most caregiver research has focused on older patients experiencing cognitive or memory disorders and other illnesses, such as cancer. ${ }^{16}$ But there remains a gap in knowledge about the impact of interventions that support or involve family members of patients with long-term, disabling trauma-related conditions, including TBI, PTSD, and polytrauma. A TBI is a nondegenerative, noncongenital insult to the brain from an external force possibly leading to permanent or temporary impairment of cognitive, physical, and psychosocial functions. PTSD is a mental health condition that is triggered by a terrifying event. Symptoms may include flashbacks, nightmares, and severe anxiety, as well as uncontrollable thoughts about the event. Polytrauma occurs when a person experiences injuries to multiple body parts and organ systems. TBI frequently occurs in polytrauma in combination with other disabling conditions, such as amputation, burns, spinal cord injury, auditory and visual damage, spinal cord injury (SCI), and post-traumatic stress disorder (PTSD).

We conducted a systematic review to describe the published literature evaluating the effect of programs that support or involve family caregivers of patients with $\mathrm{TBI},{ }^{20} \mathrm{PTSD},{ }^{21}$ and polytrauma ${ }^{22}$ and to assess the effect of these programs on caregiver, patient, and household outcomes.

\section{METHODS}

We followed a standard protocol for all steps of this review (PROSPERO: CRD42017053516). A technical report fully detailing our methods is available at https://www.hsrd.research.va.gov/publications/esp.

\section{Data Sources and Searches}

We conducted searches of MEDLINE® (via PubMed), CINAHL, and PsycINFO from 1995 through 19 December 2016 for peer-reviewed publications evaluating interventions that support or involve caregivers or families of patients with selected trauma-related illnesses (online appendix Table 1). We evaluated the bibliographies of systematic reviews and contacted content experts to identify additional relevant studies.

\section{Study Selection}

Two reviewers used prespecified eligibility criteria (online appendix Table 2) to assess all titles and abstracts. Major eligibility criteria were patients with TBI, PTSD, or polytrauma; an intervention that was designed to support or involve the caregiver or family member or designed to support the patient with involvement or support from the family member (e.g., couples therapy); and a study that used a randomized controlled trial (RCT) or quasi-experimental study design. ${ }^{23}$ Only studies conducted in Organization for Economic Cooperation and Development (OECD) countries (except countries in Asia) were included to ensure cultural comparability in family caregiving roles and expectations. Potentially eligible articles were retrieved for full-text review. Disagreements on eligibility were resolved by discussion or by a third reviewer.

\section{Data Abstraction and Quality Assessment}

Abstracted elements included patient and caregiver characteristics, intervention characteristics, comparators, outcomes of interest, and quality elements. We abstracted outcomes at end of treatment and for the longest follow-up period reported. Our general intervention framework classified six major intervention elements: (1) skills training for caregivers; (2) illness education; (3) dyadic or family therapy; (4) information about the healthcare system, community resources, or social/ emotional support; (5) day-to-day practical support (i.e., inhome respite care); and (6) financial assistance (e.g., a stipend that allows a family member to stay home). Abstractions were done by one reviewer and checked by a second.

We used the key quality criteria described by the Cochrane Effective Practice and Organization of Care Review Group (EPOC) for RCTs and nonrandomized studies. ${ }^{23} \mathrm{We}$ assigned a summary risk of bias (ROB) score to individual studies after independent raters reached consensus using Cochrane guidance: "low bias" as unlikely to alter the results seriously, "unclear bias" as raising some doubts about the results, and "high bias" as bias that may alter the results seriously. ${ }^{24}$ 


\section{Data Synthesis and Analysis}

The primary outcomes were organized as patient, caregiver, and household-level outcomes and included psychological symptoms for both patient and caregiver, patient functional status, quality of life, and disease-specific symptoms, caregiver burden, adverse effects, household economic status (e.g., changes in household income, wealth, financial strain, employment status), family function, and patient healthcare use. We described the breadth and types of studies conducted and summarized key study characteristics in tables. When at least three RCTs assessed outcome constructs that were conceptually similar, we performed meta-analyses to estimate summary effects. Continuous outcomes were summarized using the standardized mean difference because studies used different measures for the same construct. Although we focused on analyzing the follow-up measures, we used change from baseline in a few instances where baseline values differed substantially between the treatment arms. Standard deviation of change used the reported baseline and follow-up standard deviations and accounted for either exact or approximate correlation between these measures. We used the KnappHartung approach to adjust the standard errors of the estimated summary coefficients in the random effects analyses. ${ }^{25,26}$ Sensitivity analyses omitted studies judged to be high ROB. We evaluated statistical heterogeneity using visual inspection and Cochran's $Q$ and $I^{2}$ statistics. Publication bias was examined through a search of clinical trials.gov for caregiving and our three conditions of interest.

When quantitative synthesis was not feasible, we analyzed the data qualitatively. We gave more weight to the evidence from higher quality studies with more precise estimates of effect. The strength of evidence (SOE) for each key question was assessed using the approach described in the Agency for Healthcare Research and Quality's Methods Guide. ${ }^{27}$ This approach requires assessment of four domains: risk of bias, consistency, directness, and precision (online appendix Table 3). These domains were considered qualitatively for the primary outcomes, and a summary rating of high, moderate, low, or very low SOE was assigned after evaluation in the GRADE Pro software (https://gradepro.org/) and discussion by two reviewers.

\section{Role of the Funding Source}

This research was funded by the Veterans Health Administration (VHA), Office of Research and Development, Quality Enhancement Research Initiative (QUERI). QUERI staff did not participate in developing the scope of work, conducting the study, or reviewing the draft report.

\section{RESULTS}

The results are organized into three sections: literature flow, descriptive results, and outcome results. In the descriptive results section, we describe the key findings, followed by detailed descriptions of the included studies. The outcome results section describes the effects of the interventions; outcome results are organized broadly by condition; and withincondition results are organized by patient, caregiver, and household outcomes.

\section{Literature Flow}

The literature search (online appendix Fig. 1) identified 2837 unique citations from a combined search of MEDLINE, PsycINFO, and CINAHL. Another 75 articles were identified from other sources for a total of 2912 unique citations. After screening at the abstract and full-text level, 19 articles were retained for data abstraction (13 primary papers and 7 companion papers).

\section{Overview of Trials}

We identified 13 studies, $n=9 \mathrm{TBI}^{28-37}$ and $n=4 \mathrm{PTSD}^{38-41}$ that assessed psychological or rehabilitation interventions that provided support for or involved family members of patients with PTSD or TBI (Table 1). One TBI study also examined PTSD diagnoses and found frequent comorbidity (67\%) of the two. ${ }^{28}$ No intervention studies were identified for caregivers of patients assessed for polytrauma. The 13 identified studies included 10 randomized controlled trials (RCTs), 2 nonrandomized trials, and 1 interrupted time series design. ${ }^{34}$ Except for the interrupted times series study, interventions were compared with waitlist or inactive comparators in five studies, usual care in four studies, and active comparators in four studies. Our search of clinicaltrials.gov identified 14 entries that may produce applicable results in the future (online appendix Table 4).

Table 1 Evidence Profile for Family Caregiving Studies $(n=13)$

\begin{tabular}{|c|c|c|}
\hline & TBI studies $(n=9)$ & $\begin{array}{l}\text { PTSD studies } \\
(n=4)\end{array}$ \\
\hline Study designs & $\begin{array}{l}6 \mathrm{RCTs}^{28,29,31-33,35} \\
2 \text { nonrandomized } \\
\text { trials }{ }^{30,36} \\
1 \text { interrupted time } \\
\text { series }^{34}\end{array}$ & $\begin{array}{l}3 \text { RCTs } \\
1 \text { cluster RCT }\end{array}$ \\
\hline Study years & $\begin{array}{l}1995,2005 \text { (2 studies), } \\
\text { 2008, 2012, 2013, 2015, } \\
2016 \text { (2 studies) }\end{array}$ & $\begin{array}{l}1999,2008 \\
2012,2015\end{array}$ \\
\hline Number of patients & 1148 & 324 \\
\hline $\begin{array}{l}\text { Number of caregivers } \\
\text { (studies NR) }\end{array}$ & 673 (2 studies NR) & $\begin{array}{l}97 \text { (2 studies } \\
\text { NR) }\end{array}$ \\
\hline $\begin{array}{l}\text { Mean patient age } \\
\text { (range) reported in \# } \\
\text { of study arms (studies } \\
\text { NR) }\end{array}$ & $\begin{array}{l}38.7(30.3-44.6) \\
\text { reported in } 18 \text { study } \\
\text { arms ( } 2 \text { studies NR) }\end{array}$ & $\begin{array}{l}38.0(32.6-46.7) \\
\text { reported in } 9 \\
\text { study arms }\end{array}$ \\
\hline $\begin{array}{l}\text { Mean caregiver age } \\
\text { (range) reported in \# } \\
\text { studies }\end{array}$ & $\begin{array}{l}48.6(41.2-51.8) \\
\text { reported in } 6 \text { studies }\end{array}$ & $\begin{array}{l}34.5(32.2-40.7) \\
\text { reported in } 2 \\
\text { studies }\end{array}$ \\
\hline Intervention setting & $\begin{array}{l}\text { Patients living in the } \\
\text { community }\end{array}$ & $\begin{array}{l}\text { Patients living in } \\
\text { the community }\end{array}$ \\
\hline Patients are veterans & 1 study & 3 studies \\
\hline Countries & $\begin{array}{l}\text { USA (6), Canada (1), } \\
\text { UK (1), Australia (1) }\end{array}$ & $\begin{array}{l}\text { USA (4), } \\
\text { Canada }(1)^{*}\end{array}$ \\
\hline
\end{tabular}

*One study was conducted in both the USA and Canada 
The intervention target was both caregiver and patient in six studies, primarily the patient in three studies (with minimal or optional caregiver involvement in two studies ${ }^{31,35}$ ), and only the caregiver in four studies (online appendix Table 5). Reported outcomes of interest included psychological status in nine studies and caregiver burden, quality of life, and family functioning in three studies each. No studies reported on any type of adverse events. A variety of measurement instruments were utilized for each outcome category; these measures are described in online appendix Table 4. The timing of outcome measurement varied widely across studies, as intervention duration ranged from 2.5 months to 2 years.

Intervention delivery was most often one-on-one $(n=9)$ and delivered in-person. Telephonic interventions were used in five studies, usually in combination with in-person or written communication. Intervention duration ranged from 10 weeks to 2 years, with a median of 14 weeks; two studies did not report intervention duration. The number of sessions ranged from 3 to 16 ; sessions lasted from 30 min to $3 \mathrm{~h}^{32,33}$

The majority of interventions included illness education ( $n=12,92 \%)$ and skills training $(n=9,69 \%)$. Other components were psychological therapy $(n=5,38 \%),{ }^{32,36,39-41}$ social support $(n=3), 31,34,39$ written materials to complement illness education $(n=3),{ }^{30,33,35}$ and help with resource navigation $(n=3){ }^{28,31,39}$ No studies offered financial assistance or other practical assistance, such as respite care, as part of the intervention (online appendix Tables 8 and 9).

\section{Outcomes for TBI}

Key TBI outcomes are illustrated in online appendix Fig. 2; TBI studies are described in online appendix Table 5, and ROB is shown in online appendix Fig. 3. Definitions of TBI varied and included self-report of a head trauma, ${ }^{30,31,34,36}$ the Glasgow Coma Scale, ${ }^{33,35}$ and the VA Criteria for TBI. ${ }^{28}$ The ROB was judged low for two studies, ${ }^{29,35}$ unclear for three studies, ${ }^{28,32,34}$ and high for four studies. ${ }^{30,31,33,36}$

TBI: Patient Outcomes. Meta-analyses were conducted for four patient-level outcomes: functional status, including overall, physical, and social/emotional functional status, and psychological symptoms. These analyses included five RCTs (455 patients). ${ }^{28,29,31,33,35}$ Interventions evaluated across the five RCTs included a home visitation program to improve caregiver coping (Veterans In-Home Program-VIP), ${ }^{28,37}$ group psychoeducation, ${ }^{33}$ family-based telephone counseling using motivational interviewing for problem-solving,${ }^{35}$ problem-solving therapy with TBI family caregivers, ${ }^{29}$ and patient and significant other mentoring on topics such as disease education and relationship skills (i.e., building trust, problem-solving, goal-setting). ${ }^{31}$ The number of contacts across interventions was similar. For the meta-analyses, data from the last assessment time point was used and this time point generally coincided with end of treatment, except for two studies for which only data from a 3-month post-intervention follow-up was available, ${ }^{33,35}$ and one study for which only data from one month after the intervention was completed. ${ }^{31}$ Assessment time points ranged from 4 months ${ }^{28}$ to 12 months $^{35}$; two studies did not define the length of the intervention. ${ }^{32,33}$ Outcomes without a sufficient number of studies to do a meta-analysis, or from studies without an RCT design, are described qualitatively.

Functional Status. There was no intervention effect on overall functional status for TBI patients ( $n=3$ studies, SMD 0.29, $95 \% \mathrm{CI}-0.51$ to 1.08 , Fig. 1). Heterogeneity was moderate $\left(I^{2}=43.3 \%, Q=3.5, p=0.17\right)$; it is possible that the social and emotional functional status subscales in the measures of overall functional status did not represent similar constructs.

Interventions for family caregivers did not improve TBI patients' physical function $(n=4$, SMD $0.2295 \% \mathrm{CI}-0.11$ to $0.55, I^{2}=0 \%, Q=2.6, p=0.46$; Fig. 1) or emotional $/$ social function. A sensitivity analysis TBI patient physical function which omitted a high risk of bias study produced similar results (figure not shown). ${ }^{31}$ Effects on emotional/social function were inconsistent $\left(I^{2}=63.3 \%, Q=5.4, p=0.07\right)$, and thus we report the median intervention effect size and range instead of the weighted effect size ( $\mathrm{SMD}=0.42$, range -0.68 to 1.51 ) (figure not shown). ${ }^{27}$

Psychological Symptoms and TBI Symptoms. Interventions did not improve TBI patients' psychological symptoms $(n=3$; SMD $-0.25,95 \% \mathrm{CI}-0.62$ to $0.12, I^{2}=0.00 ; Q=1.1$, $p=0.58$ ) (Fig. 1). Two studies not included in a metaanalysis because of differences in study design or outcome measure examined psychological symptoms postintervention using the General Well-Being Scale $^{34}$ and the four subscales (but not full score) of the Brief Symptom Inventory (BSI) ${ }^{31}$ and found no effect of the interventions on care recipient psychological symptoms. Three studies, each examining different TBI symptom outcomes, found positive intervention effects on communication skills, ${ }^{36}$ TBI dysexecutive and memory problems, ${ }^{33}$ and patient-identified target symptoms. ${ }^{28}$

Quality of Life. One study found no intervention effect on quality of life (SMD $-0.05,95 \% \mathrm{CI}-0.41$ to 0.31 ), ${ }^{29}$ and another found significant benefit when measured by the EuroQoL (SMD 0.40, 95\% CI 0.07 to 0.74) and the Perceived Quality of Life (PQOL) scale (SMD 0.42, 95\% CI 0.08 to 0.77$){ }^{35}$

TBI: Family Caregiver Outcomes. Psychological Symptoms. We analyzed family caregiver psychological symptoms using data

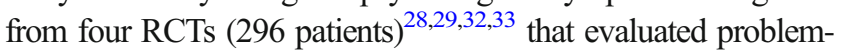
solving therapy with family caregivers, ${ }^{29,32}$ illness education and skills training, ${ }^{33}$ and VIP. ${ }^{37}$ The number of contacts across interventions ranged from 8 to 12 . Meta-analysis results found no 
a

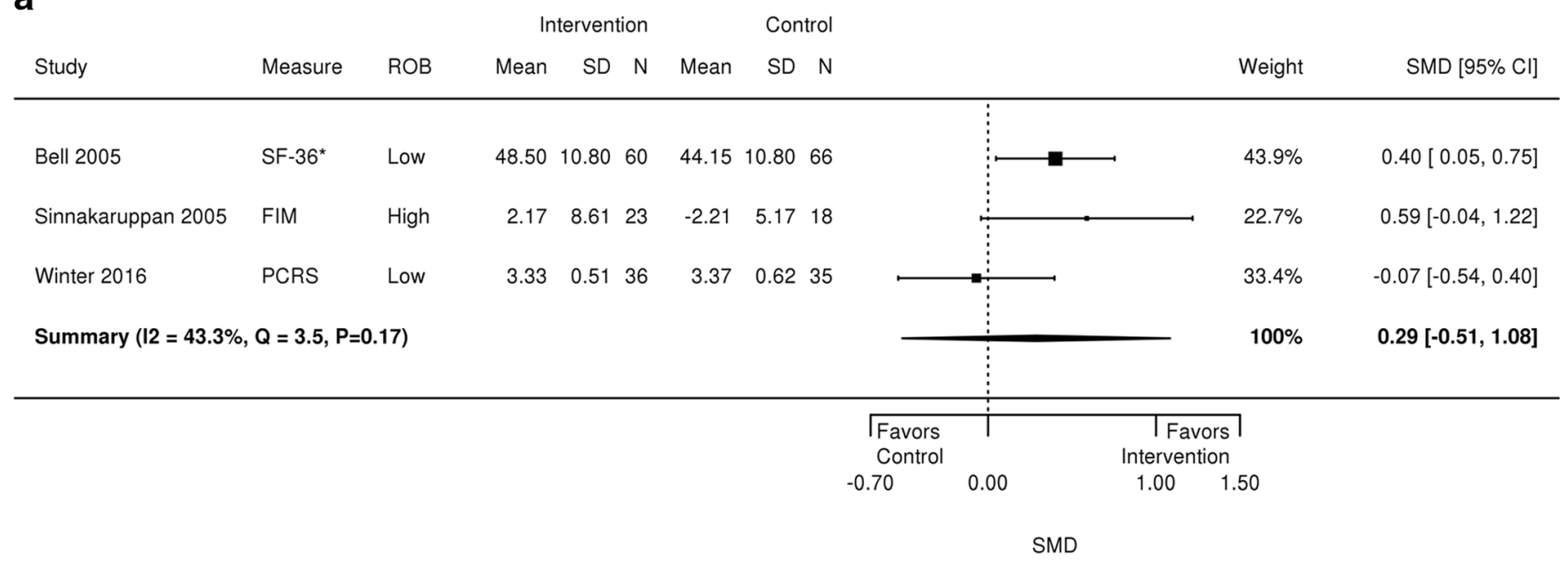

b

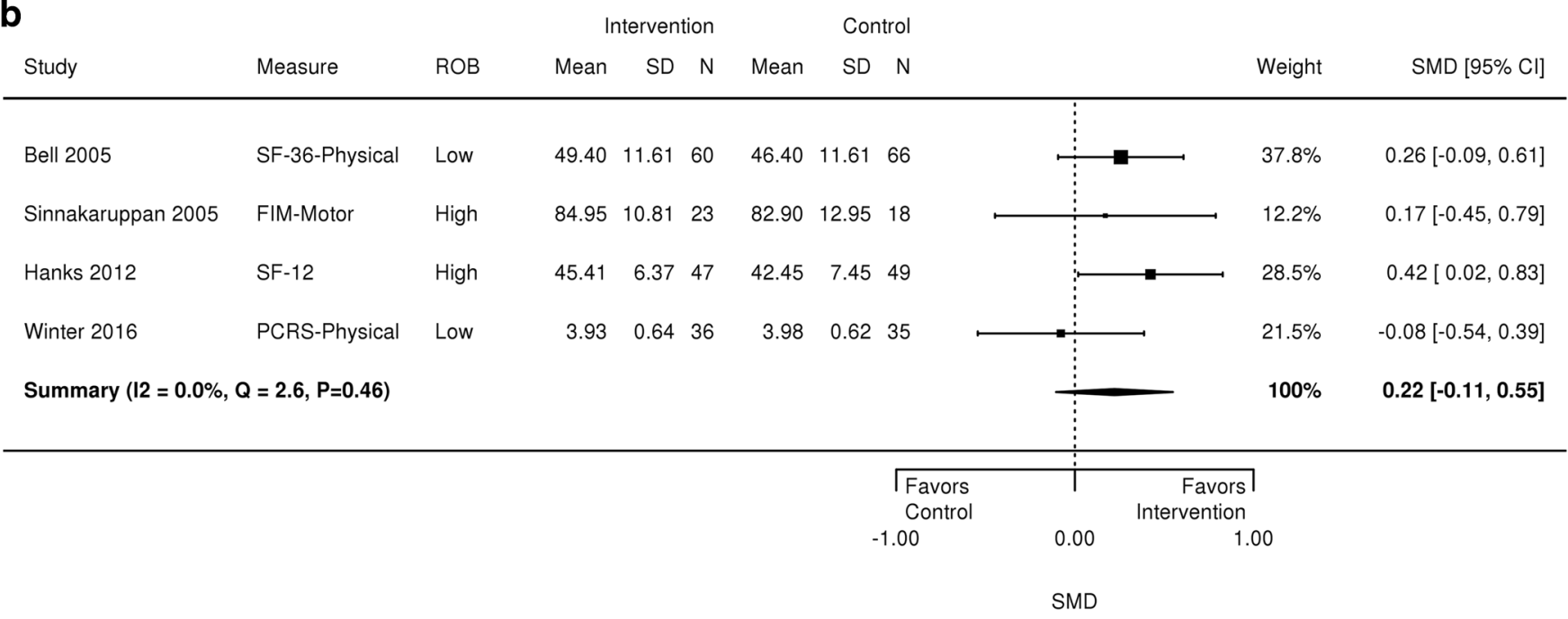

C

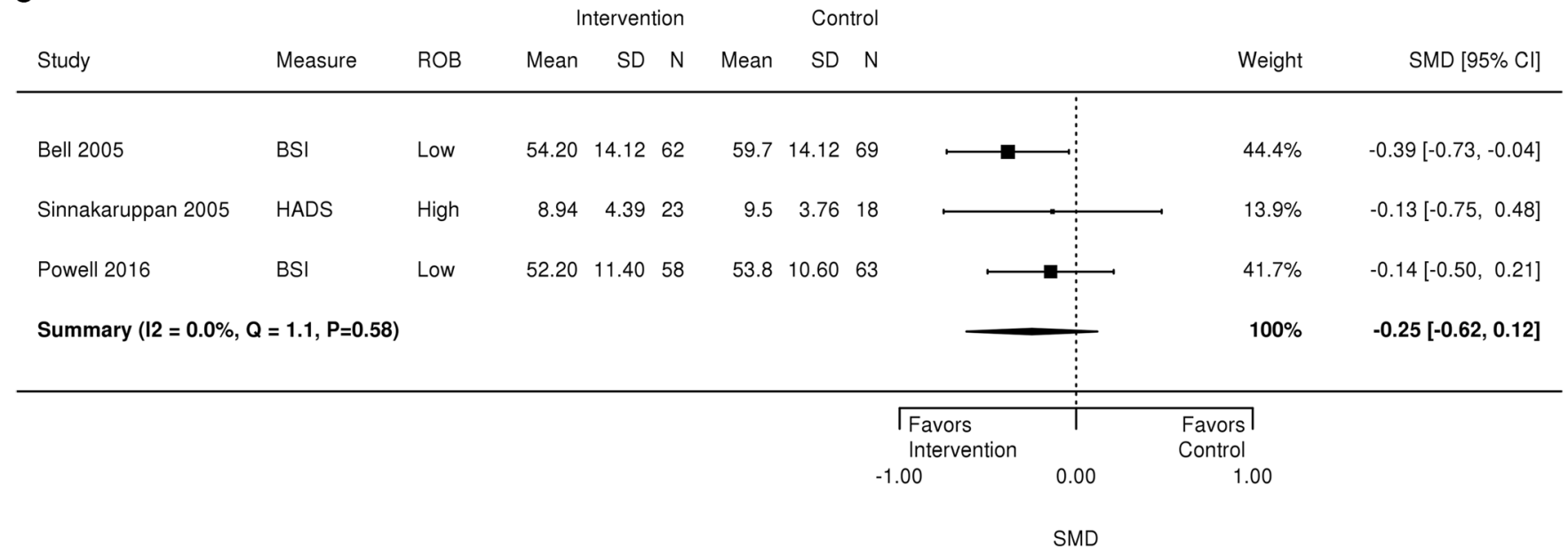

Figure 1 Forest plot of outcomes for TBI patients. BSI = Brief Symptom Inventory, FIM $=$ Functional Independence Measure, HADS $=$ Hospital Anxiety and Depression Scale, PCRS = Patient Competency Rating Scale, SF-36 = Medical Outcomes Study Short Form-36, SF-36-Physical = Medical Outcomes Study Short Form-36 Physical Function Scale, SF-12-Physical = Medical Outcomes Study Short Form-12 Physical Function Scale. a TBI patient overall function. b TBI patient physical function. c TBI patient psychological symptoms

benefit of the intervention on caregiver psychological symptoms (SMD $-0.26,95 \% \mathrm{CI}-0.57$ to $0.05, I^{2}=0.0, Q=2.1, p=0.56$ ) (Fig. 2). A sensitivity analysis that omitted a high ROB study ${ }^{33}$ found a positive effect of the interventions on caregiver psychological symptoms (SMD $-0.32,95 \% \mathrm{CI}-0.59$ to $-0.05, I^{2}=0.0, Q=0.5, p=0.78$ ) (figure not shown).

Outcomes without sufficient data for a meta-analysis are described qualitatively. Two studies found no effect of a 


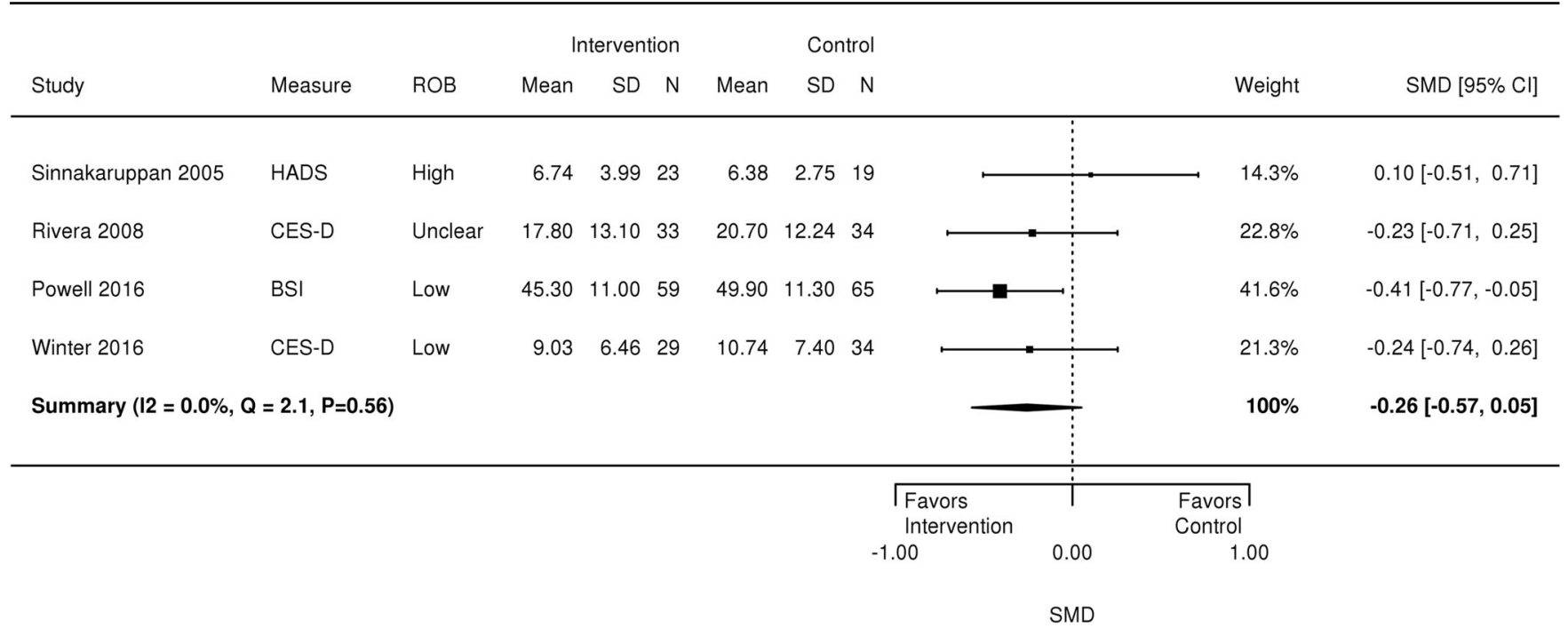

Figure 2 Forest plot of psychological symptoms for TBI caregivers. BSI = Brief Symptom Inventory, CES-D = Center for Epidemiological Studies Depression Scale, CI = confidence interval, HADS = Hospital Anxiety and Depression Scale, SD = standard deviation, SMD = standardized mean difference

family-involved treatment on quality of life ${ }^{29,32}$; however, small sample sizes $\left(n=67\right.$ enrolled $^{32} ; n=153$ enrolled $\left.^{29}\right)$ might have precluded the ability to detect significant differences. Three studies, ${ }^{30,32,37}$ which included a companion paper to the Winter et al. 2016 study, ${ }^{37}$ examined caregiver burden, but only two were RCTs, ${ }^{32,37}$ and therefore we did not have enough studies to conduct a meta-analysis. All studies showed decreased caregiver burden and similar small effect sizes, ${ }^{42}$ ranging from Cohen's $d=0.30,{ }^{32}$ Cohen's $d=$ $0.31,{ }^{37}$ to $\mathrm{SDM}=0.35,{ }^{30}$ assessed at 4 to 12 months, but this finding was statistically significant in only one of the three studies. $^{37}$

TBI: Household Outcomes. Too few studies examined household-level outcomes to conduct a meta-analysis.

Family Function. One study with high ROB found no effect on changes in family function as a result of the intervention. ${ }^{31}$

\section{Outcomes for PTSD}

PTSD studies are described in online appendix Table 6, and ROB is shown in online appendix Figure 4. All patients in the studies had a PTSD diagnosis, confirmed by a structured clinical interview (Clinician-Administered PTSD Scale) ${ }^{38,40,41}$ or supported by a symptom scale score. ${ }^{39}$ In two studies of couples' treatment, ${ }^{40,41}$ the caregiver was defined as an intimate partner or cohabiting opposite-sex partner. In another study, $89 \%$ of family participants were spouses/partners and the remainder were siblings or parents. ${ }^{38}$ One study did not describe the level or extent of family participation. ${ }^{39}$

Four RCTs (336 patients) evaluated patient-focused PTSD treatments with family member involvement and reported on family member outcomes. One high ROB three-arm trial evaluated the effect of augmenting directed exposure therapy (DTE) with behavioral family therapy (BFT) compared with DTE alone and waitlist arms. ${ }^{38}$ Two unclear ROB studies compared couples-based therapies (cognitive-behavioral conjoint therapy [CBCT-PTSD] and structured approach therapy [SAT]) to waitlist ${ }^{40}$ or family education control. ${ }^{41}$ Another high ROB study evaluated the effect of a multiple-family group intervention aimed at increasing access to mental healthcare for a community population of Bosnian refugees in the USA via a two-arm RCT. ${ }^{39}$ The variability in interventions, comparators, and outcomes precluded meaningful metaanalysis.

PTSD: Patient Outcomes. Couples-based interventions $\left(\mathrm{SAT}^{41}\right.$ and CBCT-PTSD ${ }^{40}$ ) showed consistent patterns in clinically and statistically meaningful improvement in PTSD symptoms at the end of treatment assessed by clinician interview (mean differences on CAPS ranged from 23.2 to $27.6^{40}$ ) and patient-reported symptoms (mean differences on the PTSD Checklist ranged from 8.4 to $11.8^{41}$ ). Other psychological symptoms, including patient-reported anxiety and depressive symptoms, and patient-reported interpersonal relationships also improved with these two interventions. One high ROB study found that multiple-family group sessions increased the number of mental health visits among Bosnian refugees with PTSD. ${ }^{39}$

PTSD: Family Caregiver Outcomes. Two studies reported caregiver outcomes. ${ }^{40,41,43,44}$ Using structured approach therapy (SAT), neither self-reported depressive symptoms nor anxiety symptoms improved significantly compared to family education. In an exploratory secondary analysis of couples-based treatment for PTSD (CBCT-PTSD), ${ }^{40}$ caregivers who were in the distressed range at pretreatment reported significant and reliable improvements in psychological symptoms $(57 \%[n=4])$ and demonstrated clinically 
significant improvements in depression and anxiety (28.6\% $[n=2]) .{ }^{43}$ Interpersonal relationships as reported by the caregiver did not improve. ${ }^{40,41}$

PTSD: Household Outcomes. Only one study and an associated companion paper reported limited family function outcomes. $^{40,44}$ CBCT-PTSD improved relational functioning post-treatment for caregivers who reported clinically distressed levels of psychological functioning pretreatment. ${ }^{44}$

Table 2 Strength of Evidence for Effects of Family Caregiving Interventions

\begin{tabular}{|c|c|c|c|}
\hline Outcome & $\begin{array}{l}\text { Number of } \\
\text { RCTs } \\
\text { (patients) }\end{array}$ & Findings & $\begin{array}{l}\text { Strength of } \\
\text { evidence } \\
\text { (rationale by } \\
\text { domain) }\end{array}$ \\
\hline \multicolumn{4}{|l|}{ TBI } \\
\hline \multicolumn{4}{|c|}{ Patient outcomes } \\
\hline $\begin{array}{l}\text { Overall } \\
\text { functional status }\end{array}$ & $\begin{array}{l}\quad 3(238) \\
\text { Moderate ROB, } \\
\text { consistent, } \\
\text { direct, } \\
\text { imprecise }\end{array}$ & $\begin{array}{l}\text { SMD } 0.29 \\
\text { higher }(0.51 \\
\text { lower to } 1.08 \\
\text { higher) }\end{array}$ & Moderate \\
\hline $\begin{array}{l}\text { Physical } \\
\text { functional status }\end{array}$ & $\begin{array}{l}\quad 4(334) \\
\text { Moderate ROB, } \\
\text { consistent, } \\
\text { direct, } \\
\text { imprecise }\end{array}$ & $\begin{array}{l}\text { SMD } 0.22 \\
\text { higher }(0.11 \\
\text { lower to } 0.55 \\
\text { higher) }\end{array}$ & Moderate \\
\hline $\begin{array}{l}\text { Emotional/ } \\
\text { social functional } \\
\text { status }\end{array}$ & $\begin{array}{l}\quad 3(238) \\
\text { Moderate ROB, } \\
\text { inconsistent, } \\
\text { indirect, very } \\
\text { imprecise }\end{array}$ & $\begin{array}{l}\text { SMD } 0.42 \\
\text { higher }(0.68 \\
\text { lower to } 1.51 \\
\text { higher) }\end{array}$ & Very low \\
\hline $\begin{array}{l}\text { Psychological } \\
\text { symptoms }\end{array}$ & $\begin{array}{l}\quad 3(293) \\
\text { Moderate ROB, } \\
\text { consistent, } \\
\text { direct, } \\
\text { imprecise }\end{array}$ & $\begin{array}{l}\text { SMD } 0.25 \\
\text { lower }(0.62 \\
\text { lower to } 0.12 \\
\text { higher) }\end{array}$ & Low \\
\hline \multicolumn{4}{|c|}{ Caregiver outcomes } \\
\hline $\begin{array}{l}\text { Psychological } \\
\text { symptoms }\end{array}$ & $\begin{array}{l}\quad 3(254) \\
\text { Moderate ROB, } \\
\text { consistent, } \\
\text { direct, } \\
\text { imprecise }\end{array}$ & $\begin{array}{l}\text { SMD } 0.32 \\
\text { lower* }(0.59 \\
\text { lower to } 0.05 \\
\text { lower) }\end{array}$ & Moderate \\
\hline $\begin{array}{l}\text { Caregiver } \\
\text { burden }\end{array}$ & $\begin{array}{l}3(252) \\
\text { Moderate ROB, } \\
\text { consistent, } \\
\text { direct, } \\
\text { imprecise }\end{array}$ & $\begin{array}{l}\text { Median effect } \\
\text { size } 0.31 \\
\text { (range } 0.30 \text { to } \\
0.35) p=\mathrm{NS} \\
\text { for } 2 \text { of } 3 \\
\text { studies }\end{array}$ & Low \\
\hline \multicolumn{3}{|l|}{ PTSD } & \\
\hline $\begin{array}{c}\text { PTSD } \\
\text { symptoms }\end{array}$ & $\begin{array}{l}\quad 2(97) \\
\text { Unclear ROB, } \\
\text { consistent, } \\
\text { direct, precise }\end{array}$ & $\begin{array}{l}\text { Clinically } \\
\text { improved } \\
\text { symptoms by } \\
\text { clinician } \\
\text { interview } \\
(\text { range } 23.2 \text { to } \\
27.6)^{\dagger} \text { and } \\
\text { patient report }\end{array}$ & Moderate \\
\hline $\begin{array}{l}\text { Interpersonal } \\
\text { relationships }\end{array}$ & $\begin{array}{l}\quad 2(97) \\
\text { Unclear ROB, } \\
\text { inconsistent, } \\
\text { direct, precise }\end{array}$ & $\begin{array}{l}\text { Improved as } \\
\text { reported by the } \\
\text { patient but not } \\
\text { the caregiver }\end{array}$ & Low \\
\hline
\end{tabular}

$R C T$ randomized controlled trial, $R O B$ risk of bias, SMD standardized mean difference

*SMD and SOE rating reported are from the sensitivity analyses excluding the single high risk of bias study

rClinician-administered PTSD scale

\section{Strength of Evidence}

For TBI, the SOE was rated moderate to low (Table 2) for care recipient overall function, physical function, psychological symptoms, and caregiver psychological symptoms and burden. SOE was very low for patient social/emotional function. Concerns that contributed to the low SOE were moderate to high risk of bias and imprecision. Because few studies evaluated caregiver interventions for patients with PTSD, we only rated the SOE for couples-based therapies for PTSD (moderate SOE). SOE was not rated for adverse effects or diseasespecific symptoms because the evidence was insufficient.

\section{DISCUSSION}

Family caregiver support is an important care component for individuals with cognitive impairments and chronic physical and mental illness. ${ }^{19,45,46}$ Interventions that involve family caregivers have been found to offset the negative consequences of caregiving by improving outcomes for family caregivers ${ }^{17,47,48}$ and patients ${ }^{49,50}$ with mental illness, cognitive impairment, and cancer. Our systematic review fills a gap in the literature by identifying and assessing the published literature evaluating the effect of interventions that support or involve family caregivers of patients with trauma-related illness. This is the first review to examine family caregiver interventions for patients with TBI and polytrauma and we extend evidence from a past review of caregiver interventions for PTSD $^{49}$ to include more recent studies and nonrandomized trials.

Most studies that we identified targeted patients with TBI $(n=9)$, a few examined patients with PTSD $(n=4)$, and no studies enrolled patients assessed to have polytrauma. The most commonly utilized intervention component was illness education. Other commonly used components included skills training, social support, and therapy. We found no eligible studies that assessed financial support to caregivers or patients. While individual interventions varied in delivery type, delivery mode, and intensity, most interventions addressed similar topics, including providing social support for the caregiver, improving clinical care in the home, modifying the home environment to better manage patient needs, and increasing family knowledge about healthcare resources. At least three studies reported intervention effects for each of the following outcomes: patient functional status, psychological outcomes, disease-specific symptoms, caregiver burden, caregiver psychological symptoms, and family function. Only one study examined mental health service use. Adverse intervention effects and household economic status outcomes were not reported.

The studies showed a mixed pattern of intervention effects. Results from the TBI meta-analyses showed no statistically significant effects of interventions that involved family caregivers on patient functional status, patient psychological symptoms, or caregiver psychological symptoms. Yet, heterogeneity was high, confidence intervals were wide, and SOE 
was moderate to low. Across outcomes, the direction of effects consistently favored the intervention, but it is possible that these effects were due to the moderate ROB identified among studies. Also, qualitative findings suggest that some interventions had positive effects on patient quality of life, ${ }^{35}$ TBI symptoms (e.g., communication, memory, and patientidentified symptoms), ${ }^{28,33,36}$ and caregiver burden. ${ }^{37}$ Due to the low number of studies, we were unable to perform a metaanalysis for the studies with PTSD patients. However, data were analyzed qualitatively and across studies couples-based therapies showed the most promise for improving patient PTSD symptoms, other psychological symptoms, and patient-reported interpersonal relationships. ${ }^{40,41}$ Only couples-based therapy for PTSD symptoms and TBI patient overall and physical functional status was given a moderate strength of evidence rating. All others were rated low or very low.

\section{Limitations/Future Research}

Our review was limited to OECD countries (except Asia) and articles published in English. Structured search terms may not fully capture the broad range of eligible interventions we considered. The existing literature is limited by the small number of studies and problems with study quality. We found sparse evidence in patients with PTSD. Only one study assessed overlap in PTSD and TBI and therefore we are unable to comment on how high comorbidity between the two conditions might have impacted the results of the meta-analyses. No studies examined the effects of financial support for caregivers, a strategy being deployed on a large scale in VHA. ${ }^{8}$ Few studies evaluated patient outcomes and no study reported adverse effects. Further, outcome measures varied greatly which contributed to unexplained heterogeneity in some meta-analyses and hampered our efforts to generate evidence on which caregivers and patients are most likely to benefit. For most types of interventions, there is uncertainty about the relationship between outcomes and intervention dose, mode of delivery, and components. We did not have enough studies to conduct robust assessments of publication bias. ${ }^{51}$ Relevant and active studies identified from clinicaltrials.gov identified 14 entries (online appendix Table 4), but all studies suffer similar limitations as those included in our report. Only one identified study addressed polytrauma and it was an observational study that would not have met our inclusion criteria.

This review informs best practices related to study target samples, design, and outcome measurement that could inform future research and implementation efforts. First, evidence is needed that examines caregiver interventions for patients with polytrauma. Second, more studies are needed with larger samples and randomized or quasi-experimental designs. Longitudinal studies that follow patients and caregivers for at least a year are also needed to provide sufficient time to identify changes in outcomes and test for the persistence of observed effects. Third, the use of common outcome measures would enhance synthesis across studies. Investigators should select measures that accurately capture the outcome of interest and that are reliable, pragmatic, responsive to change, and valid, such as the CES-D for depression. Fourth, of notable absence across many studies were important patient- and caregivercentered outcomes, such as intervention satisfaction and acceptability and quality of life, that might be more important and direct indicators of intervention effectiveness; future studies should include such measures. Fifth, more theoretical models, such as stress-vulnerability theory, are needed to inform discrete study goals, intervention designs, testable hypotheses, and explanations for the observed findings. Such theoretical models would provide a benchmark for more indepth analysis about what did and did not work and would thus move the field forward. Finally, we observed that many studies focused on multiple goals and may not have clearly targeted the patient or caregiver. While we were unable to test this hypothesis, it may be more effective to focus on one or two outcome goals and then refine content, delivery strategy, target participant (i.e., patient vs. caregiver), and intervention intensity to specifically address those outcomes. The highest priority evidence gaps are described in online appendix Table 10.

\section{CONCLUSIONS}

There is a growing literature about family caregiver interventions for patients with trauma-based conditions. Evidence from our meta-analyses about the impact of these interventions on patient and caregiver outcomes is inconclusive. However, the direction of effects and findings from qualitative synthesis suggest that for improving TBI and PTSD condition-related symptoms, caregiver interventions may be a promising approach.

Acknowledgments: We would like to acknowledge Liz Wing, MA, for the editorial assistance and Daniel Bradford, MD, for providing content expertise. This report is based on research conducted by the Evidence-based Synthesis Program (ESP) Center located at the Durham VA Medical Center, Durham, NC, funded by the Department of Veterans Affairs, Veterans Health Administration, Office of Research and Development, Quality Enhancement Research Initiative.

Corresponding Author: Megan E. Shepherd-Banigan, PhD, MPH; Center for Health Services Research in Primary Care Durham Veterans Affairs Medical Center, Durham, NC, USA (e-mail: mes86@duke.edu). Compliance with Ethical Standards:

The findings and conclusions in this document are those of the author(s) who are responsible for its contents; the findings and conclusions do not necessarily represent the views of the Department of Veterans Affairs or the US Government. Therefore, no statement in this article should be construed as an official position of the Department of Veterans Affairs. No investigators have any affiliations or financial involvement (e.g., employment, consultancies, honoraria, stock ownership or options, expert testimony, grants or patents received or pending, or royalties) that conflict with material presented in the report.

Conflict of Interest: The authors declare that they do not have conflict of interest. 
Financial Support: This report is based on research conducted by the Evidence-based Synthesis Program (ESP) Center located at the Durham VA Medical Center, Durham, NC, funded by the Department of Veterans Affairs, Veterans Health Administration, Office of Research and Development, Quality Enhancement Research Initiative. This work was also supported by the Center of Innovation for Health Services Research in Primary Care (CIN 13-410) at the Durham VA Medical Center. Megan Shepherd-Banigan is supported by a VA OAA HSR\&D PhD Fellowship TPH 21-00O.

\section{REFERENCES}

1. Coughlin J. Estimating the impact of caregiving and employment on well-being. Outcomes and Insights in Health Management. Available at: http://www.healthways.com/science/success-entries/estimating-theimpact-of-caregiving-and-employment-on-well-being. Accessed 22 February 2018.

2. Department of Veterans Affairs. What is polytrauma? Available at: https://www.polytrauma.va.gov/understanding-tbi/definition-andbackground.asp. Accessed 22 February 2018.

3. Ramchand R, Tanielian T, Fisher MP. Hidden Heroes: America's Military Caregivers. Santa Monica: Rand Corporation. 2014.

4. Kessler RC, Chiu WT, Demler O, Merikangas KR, Walters EE. Prevalence, severity, and comorbidity of 12-month DSM-IV disorders in the National Comorbidity Survey Replication. Arch Gen Psychiatry 2005;62(6):617-27.

5. Zaloshnja E, Miller T, Langlois JA, Selassie AW. Prevalence of long-term disability from traumatic brain injury in the civilian population of the United States, 2005. J Head Trauma Rehabil 2008;23(6):394-400.

6. Family Caregiver Alliance. National Center on Caregiving. Definitions. Available at: https://www.caregiver.org/definitions-0. Accessed 22 February 2018.

7. Public Law 111-163-Caregivers and Veterans Omnibus Health Services Act of 2010. Available at: https://www.gpo.gov/fdsys/pkg/PLAW111publ163/content-detail.html. Accessed 22 February 2018.

8. Van Houtven $\mathbf{C H}$, Smith VA, Stechuchak KM, et al. Comprehensive support for family caregivers: impact on veteran health care utilization and costs. Med Care Res Rev 2017:1077558717697015. https://doi.org/ $10.1177 / 1077558717697015$

9. Schulz R, Sherwood PR. Physical and mental health effects of family caregiving. Am J Nurs 2008;108(9 Suppl):23-7; quiz 27.

10. Coe NB, Van Houtven CH. Caring for mom and neglecting yourself? The health effects of caring for an elderly parent. Health Econ 2009; 18(9):991-1010.

11. Wilson MR, Van Houtven CH, Stearns SC, et al. Depression and missed work among informal caregivers of older individuals with dementia. J Fam Econ. 2007;28:684.

12. Jacobs JC, Van Houtven CH, Laporte A, Coyte PC. Baby Boomer caregivers in the workforce: do they fare better or worse than their predecessors J Econ Ageing 2015(6):89-101.

13. Van Houtven CH, Friedemann-Sanchez G, Clothier B, Levison D, Taylor BC, Jensen AC, et al. Is policy well-targeted to remedy financial strain among caregivers of severely injured U.S. service members? Inquiry 2012;49(4):339-51.

14. Van Houtven CH, Coe NB, Skira MM. The effect of informal care on work and wages. J Health Econ 2013;32(1):240-52.

15. Wolff JL, Spillman BC, Freedman VA, Kasper JD. A national profile of family and unpaid caregivers who assist older adults with health care activities. JAMA Intern Med 2016;176(3):372-9.

16. Dyer EA, Kansagara D, McInnes DK, Freeman M, Woods S. Mobile Applications and Internet-based Approaches for Supporting Nonprofessional Caregivers: A Systematic Review. VA Evidence-based Synthesis Program Reports. 2012. Available at: https://www.hsrd.research. va.gov/publications/esp/mobile_apps.cfm. Accessed 22 February 2018.

17. Goy E, Kansagara D, Freeman M. A Systematic Evidence Review of Interventions for Non-professional Caregivers of Individuals with Dementia. VA Evidence-based Synthesis Program Reports. 2010. Available at: https://www.hsrd.research.va.gov/publications/esp/dementiacare.cfm. Accessed 22 February 2018.
18. Meis LA, Griffin JM, Greer N, Jensen AC, Macdonald R, Carlyle M, et al. Couple and family involvement in adult mental health treatment: a systematic review. Clin Psychol Rev 2013;33(2):275-86.

19. Wolff JL, Feder J, Schulz R. Supporting family caregivers of older Americans. N Engl J Med 2016;375(26):2513-2515.

20. Medscape. Traumatic brain injury (TBI)—definition, epidemiology, pathophysiology. Available at: https://emedicine.medscape.com/article/ 326510-overview. Accessed 22 February 2018.

21. Mayo Clinic. Post-traumatic stress disorder (PTSD). Available at: https:// www.mayoclinic.org/diseases-conditions/post-traumatic-stress-disorder/symptoms-causes/syc-20355967. Accessed 22 February 2018.

22. U.S. Department of Veterans Affairs. Polytrauma/TBI system of care. Available at: https://www.polytrauma.va.gov/understanding-tbi/definition-and-background.asp. Accessed 22 February 2018.

23. Cochrane Effective Practice and Organization of Care (EPOC). EPOC Resources for review authors. 2017.Available at: epoc.cochrane.org/epocresources-review-authors.

24. Higgins JP, Altman DG, Gotzsche PC, et al. The Cochrane Collaboration's tool for assessing risk of bias in randomised trials. BMJ 2011;343:d5928.

25. DerSimonian R, Laird N. Meta-analysis in clinical trials. Control Clin Trials 1986;7(3): 177-88.

26. Knapp G, Hartung J. Improved tests for a random effects metaregression with a single covariate. Stat Med 2003;22(17):2693-710.

27. Slutsky J, Atkins D, Chang S, et al. Comparing medical interventions: AHRQ and the Effective Health Care Program. In: Agency for Healthcare Research and Quality. Methods Guide for Comparative Effectiveness Reviews [posted November 2008]. Rockville, MD. Available at: https:// www.effectivehealthcare.ahrq.gov/topics/medical-interventions-comparing/methods. Accessed 22 February 2018.

28. Winter L, Moriarty HJ, Robinson $\mathbf{K}$, et al. Efficacy and acceptability of a home-based, family-inclusive intervention for veterans with TBI: A randomized controlled trial. Brain Inj 2016;30:373-387.

29. Powell JM, Fraser R, Brockway JA, Temkin N, Bell KR. A telehealth approach to caregiver self-management following traumatic brain injury: a randomized controlled trial. J Head Trauma Rehabil 2016;31(3):18090.

30. Kreutzer JS, Marwitz JH, Sima AP, Godwin EE. Efficacy of the brain injury family intervention: impact on family members. J Head Trauma Rehabil 2015;30(4):249-60.

31. Hanks RA, Rapport LJ, Wertheimer J, Koviak C. Randomized controlled trial of peer mentoring for individuals with traumatic brain injury and their significant others. Arch Phys Med Rehabil 2012;93(8):1297-304.

32. Rivera PA, Elliott TR, Berry JW, Grant JS. Problem-solving training for family caregivers of persons with traumatic brain injuries: a randomized controlled trial. Arch Phys Med Rehabil 2008;89(5):931-41.

33. Sinnakaruppan I, Downey B, Morrison S. Head injury and family carers: a pilot study to investigate an innovative community-based educational programme for family carers and patients. Brain Inj 2005; 19(4):283-308.

34. Acorn S. Assisting families of head-injured survivors through a family support programme. J Adv Nurs 1995;21(5):872-7.

35. Bell KR, Temkin NR, Esselman PC, Doctor JN, Bombardier CH, Fraser RT, et al. The effect of a scheduled telephone intervention on outcome after moderate to severe traumatic brain injury: a randomized trial. Arch Phys Med Rehabil 2005;86(5):851-6.

36. Togher L, McDonald S, Tate R, Power E, Rietdijk R. Training communication partners of people with severe traumatic brain injury improves everyday conversations: a multicenter single blind clinical trial. J Rehabil Med 2013;45(7):637-45.

37. Moriarty $\mathbf{H}$, Winter L, Robinson $\mathbf{K}$, Piersol CV, Vause-Earland $\mathbf{T}$, Iacovone DB, et al. A randomized controlled trial to evaluate the veterans' in-home program for military veterans with traumatic brain injury and their families: report on impact for family members. PM R 2016;8(6):495-509.

38. Glynn SM, Eth S, Randolph ET, Foy DW, Urbaitis M, Boxer L, et al. A test of behavioral family therapy to augment exposure for combat-related posttraumatic stress disorder. J Consult Clin Psychol 1999;67(2):243-51.

39. Weine S, Kulauzovic Y, Klebic A, Besic S, Mujagic A, Muzurovic J, et al. Evaluating a multiple-family group access intervention for refugees with PTSD. J Marital Fam Ther 2008;34(2): 149-64.

40. Monson CM, Fredman SJ, Macdonald A, Pukay-Martin ND, Resick PA, Schnurr PP. Effect of cognitive-behavioral couple therapy for PTSD: a randomized controlled trial. JAMA 2012;308(7):700-9. 
41. Sautter FJ, Glynn SM, Cretu JB, Senturk D, Vaught AS. Efficacy of structured approach therapy in reducing PTSD in returning veterans: a randomized clinical trial. Psychol Serv 2015;12(3):199-212.

42. Cohen J. Statistical power analysis for the behavioral sciences. Routledge. Abingdon 1977.

43. Shnaider P, Pukay-Martin ND, Fredman SJ, Macdonald A, Monson CM. Effects of cognitive-behavioral conjoint therapy for PTSD on partners' psychological functioning. J Trauma Stress 2014;27(2):129-36.

44. Shnaider P, Pukay-Martin ND, Sharma S, Jenzer T, Fredman SJ, Macdonald A, et al. A preliminary examination of the effects of pretreatment relationship satisfaction on treatment outcomes in cognitive-behavioral conjoint therapy for PTSD. Couple Family Psychol 2015;4(4):229-238

45. Martire LM, Schulz R. Caregiving and Care-receiving in Later Life Recent evidence for Health Effects and Promising Intervention Approaches. In: Baum A, Revenson T, Singer J, eds. Handbook for Health Psychology. New York: Taylor and Francis. 2012.

46. Glynn SM, Cohen AN, Dixon LB, Niv N. The potential impact of the recovery movement on family interventions for schizophrenia: opportunities and obstacles. Schizophr Bull 2006;32(3):451-63.

47. Lobban F, Postlethwaite A, Glentworth D, Pinfold V, Wainwright L, Dunn G, et al. A systematic review of randomised controlled trials of interventions reporting outcomes for relatives of people with psychosis. Clin Psychol Rev 2013;33(3):372-82.
48. Yesufu-Udechuku A, Harrison B, Mayo-Wilson E, Young N, Woodhams $\mathbf{P}$, Shiers D, et al. Interventions to improve the experience of caring for people with severe mental illness: systematic review and meta-analysis. Br J Psychiatry 2015;206(4):268-74.

49. Meis L, Griffin J, Greer N, Jensen A, Carlyle M, MacDonald R, et al. Family involved psychosocial treatments for adult mental health conditions: a review of the evidence. VA Evidence-based Synthesis Program Reports. 2012. Available at: https://www.hsrd.research.va.gov/publications/esp/family-interventions.cfm. Accessed 22 February 2018.

50. Griffin JM, Meis L, Greer N, Jensen A, MacDonald R, Rutks I, et al. Effectiveness of family and caregiver interventions on patient outcomes among adults with cancer or memory-related disorders: a systematic review. VA Evidence-based Synthesis Program Reports. 2013. Available at: https://www.hsrd.research.va.gov/publications/esp/caregiver-interventions.cfm. Accessed 22 February 2018.

51. Sterne JA, Sutton AJ, Ioannidis JP, Terrin N, Jones DR, Lau J, et al. Recommendations for examining and interpreting funnel plot asymmetry in meta-analyses of randomised controlled trials. BMJ 2011;343 d4002. 